\title{
Regulation of Interleukin-6 Expression in Human Decidual Cells and Its Potential Role in Chorioamnionitis
}

\author{
Charles J. Lockwood, ${ }^{*}$ William K. Murk, ${ }^{*}$ \\ Umit A. Kayisli, ${ }^{*}$ Lynn F. Buchwalder, ${ }^{*}$ \\ S. Joseph Huang, ${ }^{*}$ Felice Arcuri, ${ }^{\dagger}$ Min Li, ${ }^{*}$ \\ Arun Gopinath, ${ }^{\ddagger}$ and Frederick Schatz* \\ From the Departments of Obstetrics, Gynecology and \\ Reproductive Sciences, ${ }^{*}$ and Pathology, ${ }^{\ddagger}$ Yale University School of \\ Medicine, New Haven, Connecticut; and the Department of \\ Human Pathology and Oncology, University of Siena, \\ Siena, Italy
}

Chorioamnionitis frequently precedes both genital tract and placental inflammation and is both a primary cause of maternal morbidity and a major antecedent of preterm premature rupture of the membranes (PPROM) as well as preterm delivery (PTD). In most cases of chorioamnionitis, neutrophils dominate the decidua. In a subset of these cases, a predominance of monocytes is uniquely associated with both neonatal intraventricular hemorrhage and death. The multifunctional cytokine, interleukin- 6 , promotes local monocyte dominance via several mechanisms. In this study, immunostaining of placental sections revealed significantly higher interleukin-6 HSCOREs in decidual cells (DCs) but not in interstitial trophoblasts, in chorioamnionitis versus gestational agematched control placentas $(P<0.05)$. In confluent leukocyte-free term DCs, secreted interleukin-6 levels in incubations with estradiol-17 $\beta$ were increased 2500 -fold by IL-1 $\beta$ ( $P<0.05)$. This up-regulation was inhibited by more than $50 \%$ in parallel incubations that included medroxyprogesterone acetate $(n=12$, $P<0.05)$. Western blotting data confirmed these enzyme-linked immunosorbent assay results; quantitative RT-PCR findings demonstrated corresponding changes in interleukin-6 mRNA levels. Specific inhibitors of signaling for both nuclear factor- $\kappa \mathrm{B}$ activation and p38-mitogen-activated protein kinase, but not for protein kinase $C$, significantly decreased IL-1 $\beta$-enhanced interleukin- 6 expression levels in cultured DCs. In conclusion, in situ and in vitro results indicate that significantly enhanced interleukin- 6 expres- sion levels in DCs during chorioamnionitis could be pivotal in skewing decidual monocyte differentiation to macrophages. (Am J Pathol 2010, 177:1755-1764; DOI: 10.2353/ajpath.2010.090781)

During human pregnancy, chorioamnionitis (CAM) frequently precedes genital tract and placental inflammation. It is a primary cause of maternal morbidity and a major antecedent of preterm premature rupture of the membranes (PPROM) and preterm delivery (PTD). ${ }^{1}$ The latter complicates about $13 \%$ of live births in the United States and is the leading cause of perinatal morbidity and mortality. ${ }^{2,3}$ During CAM, microbial species usually first ascend from the vagina and cervix to the uterus where they induce deciduitis. Despite the presence of intact membranes, microorganisms can ultimately invade the chorion, amnion, amniotic fluid, and fetus. Although positive microbial cultures are found in the amniotic fluid in $23 \%$ of women with PPROM, ${ }^{4,5} 19 \%$ displayed no signs of overt amniotic fluid infection. ${ }^{5}$ However, these samples contained elevated levels of neutrophil collagenase and elastase ${ }^{5,6}$ suggesting that pathogens remained localized to the decidua or the inciting microorganisms escaped detection. ${ }^{5}$

Recently, the large prospective Alabama Preterm Birth Study confirmed the strong association between CAM and the detection of bacterial infections. This study also observed a positive correlation between neutrophil infiltration of the fetal membranes, chorionic plate, and umbilical cord, which serve as markers of CAM, with positive intrauterine bacterial cultures and the occurrence of both

Supported by the National Institutes of Health (grant 1-R01-HL070004-04 to C.J.L.), the National Institute of Child Health and Human Development (grant 1-P01-HD054713-09 to C.J.L. and 5R01HD056123-02 to S.J.H.), and the Prematurity Research Initiative Program, March of Dimes Foundation (grant 21-FY05-1249 to C.J.L.).

Accepted for publication June 18, 2010.

Address reprint requests to Frederick Schatz, Ph.D., Department of Obstetrics, Gynecology and Reproductive Sciences, Yale University, School of Medicine. 333 Cedar St., P.O. Box 208063, New Haven, CT 06520-8063. E-mail: frederick.schatz@yale.edu. 
the neonatal inflammatory response syndrome and necrotizing enterocolitis. ${ }^{7}$ However, in a significant subset of cases, a mononuclear infiltrate in the fetal membranes and decidua basalis proved to be a harbinger of neonatal intraventricular hemorrhage. Specifically, mononuclear cell infiltration was present in $10 \%$ of the placental free membranes and decidua basalis, and within this group there was a $24 \%$ increase in neonatal intraventricular hemorrhage. This study also found a positive correlation between PTD and significantly elevated umbilical cord blood levels of interleukin (IL)-6. ${ }^{7}$ The latter is a multifunctional cytokine that regulates hematopoiesis, the acute phase reaction, and both pro- and anti-inflammatory events. ${ }^{8}$ Our laboratory recently demonstrated that decidual cells (DCs), the predominant endometrial cell type throughout pregnancy ${ }^{9}$ are a major source of elevated maternal plasma IL-6 levels ${ }^{10}$ implicated in inducing systemic endothelial cell activation and vascular damage in preeclampsia. ${ }^{11}$

In the current study we hypothesized that DCs could also contribute to the well documented CAM-related increase in IL-6 levels in maternal plasma ${ }^{12}$ as well as cervical and amniotic fluid IL-6 levels ${ }^{13}$ that reliably predict PPROM and PTD ${ }^{14}$ while acting as an autocrine/ paracrine modulator of the local immune cell population. To shed light on these questions, immunohistochemistry was used to localize IL-6 at the maternal-placental interface in DCs of placental sections from patients with CAM and gestational age-matched control placentas. The effects of IL-1 $\beta$, a classic proinflammatory cytokine present at elevated levels in the amniotic fluid of women with $\mathrm{CAM},{ }^{15}$ were evaluated on IL-6 mRNA and protein expression in cultured human term DCs. In these experiments, IL-1 $\beta$ was added with either estradiol $\left(E_{2}\right)$ as the control incubation or with $\mathrm{E}_{2}$ plus medroxyprogesterone acetate (MPA) to mimic the steroid milieu of pregnancy. To eliminate the confounding effects of resident immune cells, experimental incubations were performed with DCs that were passaged until fluorescence-activated cell sorter analysis indicated that they were essentially leukocyte-free. To elucidate a potential mechanism regulating IL-1 $\beta$-enhanced IL-6 expression in human decidual cells, experimental incubations included specific inhibitors of the intracellular signal transduction pathways for p38 mitogen-activated protein kinase (MAPK), protein kinase $\mathrm{C}(\mathrm{PKC})$, and nuclear factor (NF)- $\kappa \mathrm{B}$ activation, which are all known to mediate IL- $1 \beta$-enhanced IL-6 expression. ${ }^{16,17}$ A functional in vitro assay determined whether elevated IL-6 levels in the conditioned medium of IL-1 $\beta$-treated term DCs could promote differentiation of monocytes away from dendritic cells and toward macrophages.

\section{Materials and Methods}

\section{Patients and Tissue}

\section{Immunohistochemistry}

After written informed consent was received, biopsy samples of decidua basalis were obtained from the cen- tral portion of the maternal side of vaginally delivered placentas from patients with CAM-related PTDs $(n=10)$ and idiopathic gestational age-matched preterm control subjects $(n=9)$. Mean \pm SD gestational ages for CAMcomplicated and control pregnancies were $35.4 \pm 6.0$ and $35.5 \pm 2.8$ weeks, respectively $(P=0.957)$. None of these sections were marginal, and none were taken from any women with placenta previa. Control patients had no clinical evidence of CAM including fever, leukocytosis, or tender uterus, and their placental specimens were histologically examined to rule out conditions of acute or chronic inflammation such as CAM and chronic villitis and decidual hemorrhage (ie, abruption). CAM specimens were histologically defined as having more than 10 neutrophils per high-power field in the subchorionic space, chorion, or placental plate, based on the criteria of Naeye ${ }^{18}$ CAM was also clinically diagnosed as maternal fever $\left(>37.8^{\circ} \mathrm{C}\right)$, uterine tenderness, foul-smelling amniotic fluid or visualization of pus at the time of the speculum examination, maternal tachycardia $(\geq 100$ beats $/ \mathrm{min}$ ), and fetal tachycardia ( $\geq 160$ beats $/ \mathrm{min}) .{ }^{19} \mathrm{All}$ specimens were collected at Yale-New Haven Hospital, and collection was approved by the Yale Human Investigation Committee.

\section{Decidua Isolation}

After written informed consent was received, placentas and attached fetal membranes were obtained from patients with uncomplicated pregnancies undergoing repeat cesarean deliveries at term at Yale-New Haven Hospital under Human Investigation Committee approval. None of the patients from whom specimens were obtained was in labor. The decidua was taken from the central portion of the maternal side of the placenta, separated from the amniochorionic tissues, and a small portion of the former was formalin-fixed and paraffin-embedded and then examined histologically for signs of underlying acute and chronic inflammation. The remainder was used for the isolation and culturing of DCs.

\section{Immunohistochemistry}

Five-micrometer sections of formalin-fixed, paraffin-embedded tissues were deparaffinized in xylene and rehydrated in a descending ethanol series. Antigen retrieval was performed by boiling the slides in citrate buffer ( 10 $\mathrm{mmol} / \mathrm{L} ; \mathrm{pH}$ 6.0) for 15 minutes, and endogenous peroxidase was blocked by immersing the slides in 3\% hydrogen peroxide (in 50\% methanol/50\% distilled water) for 15 minutes. The slides were then incubated with 5\% blocking horse serum in Tris-buffered saline (TBS) in a humidified chamber for 30 minutes at room temperature. After excess serum was blotted off, serial sections were incubated with mouse monoclonal anti-human IL-6 antibody at $10 \mu \mathrm{g} / \mathrm{ml}$ in $1 \%$ blocking horse serum in TBS (R\&D Systems, Minneapolis, MN) or mouse monoclonal anti-vimentin antibody (1:100 dilution in TBS) (DakoCytomation, Carpinteria, CA) overnight at $4^{\circ} \mathrm{C}$ in a humidified chamber. Slides were also stained with nonspecific 
mouse IgG isotype-matched antibodies at the same concentrations to serve as negative controls. After being washed three times for 5 minutes in TBS, the slides were incubated with biotinylated horse anti-mouse secondary antibody (Vector Laboratories, Burlingame, CA), diluted 1:400 in TBS, for 30 minutes at room temperature. The antigen-antibody complex was visualized with an avidinbiotin-peroxidase kit (Vector Laboratories). Diaminobenzidine (3,3-diaminobenzidine tetrahydrochloride dehydrate) (Vector Laboratories) was used as the chromogen. The slides were then counterstained with hematoxylin and mounted.

IL-6 immunostaining intensity was semiquantitatively evaluated by HSCORE, using the following categories: 0 (no staining), 1+ (weak, but detectable staining), 2+ (moderate staining), and $3+$ (intense staining). An HSCORE value was determined for each specimen by calculating the sum of the percentages of cells that stained at each category and multiplying that by the value of the intensity category, using the formula HSCORE $=\Sigma_{i} i^{*} P_{i}$, where $i$ represents the intensity category and $P_{i}$ is the corresponding percentage of cells. For each slide, three different fields and 100 cells per field were evaluated microscopically at a $\times 20$ objective magnification. The percentage of cells staining at each intensity category within each field was evaluated at different times by two blinded investigators, and the average score of both were used.

\section{Isolation and Culture of DCs}

The decidua was scraped from the maternal surface of the chorion, minced, and digested in Ham's F-10 + 10\% charcoal-stripped calf serum (Flow Laboratories, Rockville, MD) containing $25 \mathrm{mg} / \mathrm{ml}$ of collagenase (200 U/mg) (Worthington Biochemical Corp., Freehold, NJ) in a shaking water bath at $37^{\circ} \mathrm{C}$ for 30 minutes. After addition of 6.25 units of DNase (Sigma-Aldrich, St. Louis, $\mathrm{MO}$ )/ml of digestate, the incubation was continued for another 45 minutes. Cell clusters in the final digestate were dissociated via aspiration with a 23-gauge needle. The isolated cells were centrifuged at $1500 \mathrm{rpm}$ for 5 minutes at $4^{\circ} \mathrm{C}$ and then washed three times in Ham's F-10, and the resulting cell pellet was resuspended $(1 \mathrm{~g}$ of tissue $/ \mathrm{ml})$ in 20\% Percoll (Sigma-Aldrich), layered onto a (60\%:50\%: $40 \%$ ) discontinuous Percoll gradient, and centrifuged at $22,000 \mathrm{rpm}$ for 20 minutes at $4^{\circ} \mathrm{C}$. The top cell layer was collected, washed, resuspended in Ham's F-10, and centrifuged at $1500 \mathrm{rpm}$ for 5 minutes at $4^{\circ} \mathrm{C}$. After this procedure was repeated, the cell pellet was resuspended in $40 \%$ Percoll ( $1 \mathrm{~g}$ of tissue $/ \mathrm{ml}$ ), layered on a discontinuous (55\%:50\%:40\%) Percoll gradient, and centrifuged at 22,000 rpm for 20 minutes at $4^{\circ} \mathrm{C}$. The top cell layer was washed twice in serum-free Ham's F-10 and centrifuged at $500 \mathrm{rpm}$ for 5 minutes at $4^{\circ} \mathrm{C}$. The cell pellet was resuspended in Ham's F-10 $+10 \%$ charcoalstripped calf serum, and decidual cells were counted in a hemocytometer. After the isolation procedure, trypan blue exclusion indicated that more than $95 \%$ of isolated cells were viable.
Isolated decidual cells $\left(5 \times 10^{5}\right.$ cells $\left./ \mathrm{ml}\right)$ were suspended in basal medium, a phenol red-free 1:1 v/v mix of Dulbecco's modified Eagle's medium (Invitrogen, Carlsbad, CA) and Ham's F-12 (Flow Laboratories) with 100 $\mathrm{U} / \mathrm{ml}$ penicillin, $100 \mu \mathrm{g} / \mathrm{ml}$ streptomycin, and $0.25 \mu \mathrm{g} / \mathrm{ml}$ Fungizone supplemented with 10\% charcoal-stripped calf serum. The cells were seeded onto polystyrene tissue culture dishes coated with $2 \%$ type B gelatin (SigmaAldrich). The cultures were grown to confluence in a standard $95 \%$ air- $5 \% \mathrm{CO}_{2}$ incubator at $37^{\circ} \mathrm{C}$ and passaged three times. Fluorescent antibody cell sorting for the presence of $\mathrm{CD}_{4} 5^{+}$demonstrated that unpassaged cultures contained 12 to $15 \%$ CD $45^{+}$cells, whereas passaged cultures were $>99 \%$ negative for this common leukocyte marker. The latter were used for experimental cell incubations. The cultured cells were vimentin-positive and cytokeratin-negative. Cultured cells also showed decidualization-related morphological changes and expressed biochemical end points of decidualization including enhanced tissue factor and plasminogen-activator inhibitor-1 and reduced interstitial collagenase and stromelysin-1 under the influence of progestin (data not shown).

\section{Experimental Cell Incubations}

Confluent decidual cells were primed for 7 days in basal medium supplemented with $10 \%$ charcoal-stripped calf serum containing either vehicle control $(0.1 \%$ ethanol), $10^{-8} \mathrm{~mol} / \mathrm{L} \mathrm{E}_{2}, 10^{-7} \mathrm{~mol} / \mathrm{L}$ MPA (Sigma-Aldrich) or $\mathrm{E}_{2}$ plus MPA with one change of medium. Because circulating levels of both $E_{2}$ and progesterone are high during the third trimester, $E_{2}$ was used with MPA to mimic the gestational steroidal milieu. MPA was used in place of progesterone because the latter is rapidly metabolized in vitro. ${ }^{20}$ The cultures were washed twice with PBS and switched to a serum-free defined medium (DM) consisting of basal medium plus ITS+ premix (BD Biosciences, Bedford, MA), $5 \mu \mathrm{mol} / \mathrm{L} \mathrm{FeSO}_{4}, 0.5 \mu \mathrm{mol} / \mathrm{L} \mathrm{ZnSO}_{4}, 1$ $\mathrm{nmol} / \mathrm{L} \mathrm{CuSO}{ }_{4}, 20 \mathrm{nmol} / \mathrm{L} \mathrm{Na}_{2} \mathrm{SeO}_{3}, 50 \mu \mathrm{g} / \mathrm{ml}$ ascorbic acid (Sigma-Aldrich), and $50 \mathrm{ng} / \mathrm{ml}$ epidermal growth factor (BD Biosciences, San Jose, CA). The corresponding vehicle or steroid(s) with and without 0.01 to $10 \mathrm{ng} / \mathrm{ml}$ of IL-1 $\beta$ (R\&D Systems) was added to the DM.

In a parallel set of experiments, the cultured DCs were also incubated with or without the following specific inhibitors within ranges recommended by the manufacturer (EMD Chemicals Inc., Gibbstown, NJ): either a p38 MAPK inhibitor (p38KI) at $10^{-5} \mathrm{~mol} / \mathrm{L}$ (SB203580), or its corresponding negative control (p38KI neg cont) at $10^{-5}$ $\mathrm{mol} / \mathrm{L}$ (SB202474), or a protein kinase C inhibitor at $10^{-7}$ $\mathrm{mol} / \mathrm{L}$ (calphostin $\mathrm{C}$ ), or an NF- $\kappa \mathrm{B}$ activation inhibitor at $10^{-5} \mathrm{~mol} / \mathrm{L}$ (NF- $\kappa \mathrm{B}$ activation inhibitor III). All of the inhibitors and negative control were added as pretreatments for 30 to 60 minutes before the addition of $1 \mathrm{ng} / \mathrm{ml} \mathrm{IL-1 \beta}$.

After the test period, cells were harvested by scraping in ice-cold lysis buffer solution of Tris-buffered saline with $1 \%$ Triton $\mathrm{X}-100,1 \mathrm{mmol} / \mathrm{L}$ phenylmethanesulfonyl fluoride (Sigma-Aldrich), and Complete Protease Inhibitor Cocktail (Roche, Mannheim, Germany) and then briefly 
sonicated. Conditioned medium supernatants and cell lysates were stored at $-70^{\circ} \mathrm{C}$. Total RNA was extracted from a different set of parallel incubations (6 hours) with Tri Reagent (Sigma-Aldrich).

\section{Enzyme-Linked Immunosorbent Assay}

Total cell protein levels were measured by a modified Lowry assay (Bio-Rad Laboratories, Hercules, CA). An enzyme-linked immunosorbent assay (ELISA) kit from R\&D Systems was used to measure IL-6 levels in the cell-conditioned DM according to the manufacturer's instructions. The sensitivity of the ELISA is $0.7 \mathrm{pg} / \mathrm{ml}$ with intra-assay and interassay coefficients of variation of 3.1 and $2.7 \%$, respectively.

\section{Western Blotting}

Western blot analysis was performed on conditioned DM supernatants that were concentrated up to ninefold using centrifugal filter devices with a 3000 molecular weight cutoff (Microcon, Millipore Corporation, Bedford, MA). For some of the blots a positive control was also used (10 ng/lane of recombinant human IL-6, R\&D Systems). The concentrated supernatants and positive control were diluted 1:1 in Laemmli nonreducing sample buffer and then boiled for 3 minutes. The centrifuged media and positive control were subjected to electrophoresis on either a 10 to $20 \%$ SDS-polyacrylamide linear gradient Tris- $\mathrm{HCl}$ gel (Bio-Rad Laboratories) or 12\% SDS-polyacrylamide TGX gel (Bio-Rad Laboratories) with subsequent electroblotting transfer onto a $0.2-\mu \mathrm{m}$ nitrocellulose membrane (Bio-Rad Laboratories). After transfer, the membrane was blocked overnight in TBS with $4 \%$ nonfat dry milk and then incubated for 2 hours with $0.2 \mu \mathrm{g} / \mathrm{ml}$ mouse antihuman IL-6 monoclonal antibody (R\&D Systems). Membranes were rinsed in PBS and $0.2 \%$ Tween 20 before and after incubation with horseradish peroxidase-conjugated anti-mouse IgG (ICN Biomedicals, Aurora, $\mathrm{OH}$ ). Chemiluminescence was detected with ECL reagents (PerkinElmer Life and Analytical Sciences, Boston, MA) and autoradiography film (Amersham Pharmacia, Little Chalfont, Buckinghamshire, UK) according to the manufacturer's instructions.

\section{Real-Time Quantitative RT-PCR}

To verify that the IL- 6 and $\beta$-actin probes yielded the correct bands, extracted RNA from experimental cell incubations were subjected to semiquantitative RT-PCR using a kit from Invitrogen, performing 35 cycles with the Mastercycler (Eppendorf, Westbury, NY). To perform quantitative real-time RT-PCR, reverse transcription was initially performed with avian myeloblastosis virus reverse transcriptase (Invitrogen). A quantitative standard curve was created using cDNA with a Roche LightCycler (Roche, Indianapolis, IN) by monitoring increasing fluorescence of PCR products during amplification. On establishing the standard curve, quantification of the unknowns was determined with the Roche LightCycler and adjusted to the quantitative expres- sion of $\beta$-actin from the corresponding unknowns. Melting curve analysis determined the specificity of the amplified products and the absence of primer-dimer formation. All products obtained yielded correct melting temperatures. Products were then run on a $1.2 \%$ agarose gel along with a 100-bp DNA ladder and then stained with ethidium bromide for visualization. The following primers were synthesized and gel-purified at the Yale DNA Synthesis Laboratory, Critical Technologies: $\beta$-actin: forward 5'-CGTACCACTGGCATCGTGAT-3' and reverse 5'GTGTTGGCGTACAGGTCTTTG-3', 452 bp and IL-6: forward 5'-ATGCAATAACCACCCCT-3' and reverse 5'AGTGTCCTAACGCTCATAC-3', 277 bp.

\section{Functional Assay for in Vitro Monocyte Differentiation}

\section{Monocyte Culture}

Monocytes were isolated from peripheral blood of healthy donors by Ficoll-Paque (GE Healthcare, Piscataway, NJ) density gradient centrifugation and then purified using anti-CD14-paramagnetic beads according to the manufacturer's instructions (Miltenyi Biotec, Auburn, CA). Purified monocytes were seeded at $1 \times 10^{6}$ cells/ well in six-well plates containing $1 \mathrm{ml}$ of $A I M-V$ serum-free medium (Invitrogen).

\section{Term DC Culture}

Confluent term DC monolayers were incubated for 24 hours with $10^{-8} \mathrm{~mol} / \mathrm{L} \mathrm{E}_{2}$ or $\mathrm{E}_{2}+\mathrm{IL}-1 \beta(1 \mathrm{ng} / \mathrm{ml})$ and collected using sterile technique (see "Isolation and Culture of DCs" and "Experimental Cell Incubations" described above). A neutralizing antibody against human IL-1 $\beta$ (R\&D Systems) was added at $1 \mu \mathrm{g} / \mathrm{ml}$ (approximately a twofold excess) to this conditioned DM for 2 hours followed by its removal using protein $\mathrm{G}$ Sepharose (Zymed Laboratories, South San Francisco, CA).

\section{Monocyte and Conditioned DM from DCs Culture}

Monocytes in the six-well plates were incubated for 5 days with the conditioned DM from the term DC cultures plus an antibody against human IL-6 ( $\alpha$-IL6, R\&D Systems) at $15 \mu \mathrm{g} / \mathrm{ml}$ (approximately a threefold excess). Using a modified protocol ${ }^{21}$ that differentiates monocytes to macrophages and dendritic cells, $30 \mathrm{ng} / \mathrm{ml}$ of recombinant human granulocyte macrophage-colony (GM)stimulating factor (CSF), $10 \mathrm{ng} / \mathrm{ml}$ of recombinant human $\mathrm{IL}-4$, and $20 \mathrm{ng} / \mathrm{ml}$ of recombinant human macrophageCSF (M-CSF) (R\&D Systems) were added to the culture medium. Fresh medium (30\% volume) containing equal amounts of M-CSF, GM-CSF, and IL-4 was added to the conditioned DM on day 3. The expression of cell surface markers was determined by flow cytometric analysis using anti-human CD11C-FITC (for dendritic cells), CD68$\mathrm{PE}$, or CD14-FITC monoclonal antibody (for macrophages) (R\&D Systems). 


\section{Statistical Analysis}

Comparisons of control and treatment groups were performed with the Kruskal-Wallis analysis of variance on ranks test followed by either the Student-Newman-Keuls post hoc test (when the groups were of equal sample size) or Dunn's post hoc test (when the groups were of unequal sample size). $P<0.05$ represented statistical significance. Gestational ages were normally distributed and compared by Student's $t$-test. HSCOREs from the immunohistochemical analysis of control and CAM samples were normally distributed (Kolmogorov-Smirnov test) and analyzed by one-way analysis of variance, followed by post hoc Holm-Sidak testing.

\section{Results}

\section{IL-6 Immunoreactivity Is Elevated in DCs in CAM-Complicated Specimens}

Serial sections of CAM-complicated (Figure 1, A and B) and control (Figure 1, C and D) decidua were immuno-

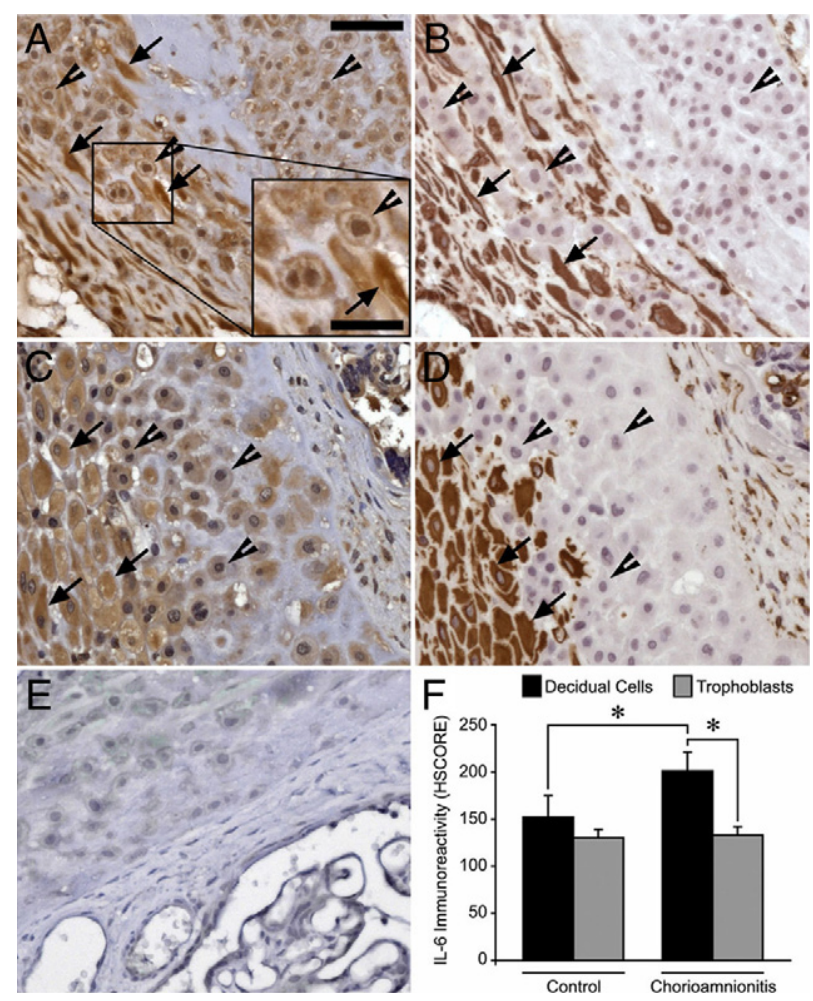

Figure 1. Immunohistochemical analysis of IL-6 expression in CAM-complicated decidua. CAM-complicated (A and $\mathbf{B})$ and control (C and $\mathbf{D})$ decidual specimens were immunostained to detect expressed IL- 6 and vimentin in serial sections. Vimentin staining identified DCs (B and D). IL-6 immunoreactivity was more intense in decidual cells (arrows) of CAM-complicated specimens (A) than control specimens (C). Interstitial trophoblasts (arrowheads) displayed similar levels of IL-6 immunoreactivity in both specimen groups, but the localization of the staining was more perimembranous in CAM-complicated specimens, particularly when immediately adjacent to DCs (A, inset). The inset in $\mathbf{A}$ is a magnification of the outlined area. E: Staining with an isotype-matched, negative, control antibody. F: IL-6 immunoreactivity HSCOREs (mean \pm SEM) in control $(n=9)$ and CAM-complicated ( $n=$ 10) specimens. ${ }^{*} P<0.05$ in both CAM-complicated versus control DCs and DCs versus interstitial trophoblast in CAM-complicated specimens and Scale bars: $50 \mu \mathrm{m}$ (A-F); $25 \mu \mathrm{m}$ (inset). stained for either IL-6 or vimentin. DCs were identified by positive vimentin staining and morphologically by their larger cell size and larger eurochromatic nuclei compared with vimentin-positive decidual leukocytes (Figure 1, B and D). Immunoreactivity for IL-6 was greater in DCs from CAM-complicated (Figure 1A) versus control specimens (Figure 1C). In CAM-complicated but not control specimens IL-6 immunoreactivity was significantly greater in DCs than in interstitial trophoblasts. In contrast with cytoplasmic IL-6 immunostaining in DCs, IL-6 immunostaining in interstitial trophoblasts was perimembranous and particularly prominent in trophoblasts adjacent to DCs; this effect was more prominent in CAMcomplicated specimens (Figure 1A). Immunostaining with an isotype-matched negative control antibody revealed no staining (Figure 1E). HSCORE analysis (Figure 1F) confirmed that IL-6 staining in DCs of CAM-complicated specimens was significantly higher than in those of control specimens (HSCORE mean \pm SEM: $201 \pm 20$ versus $152 \pm 23$, respectively; $P<0.05$ ) and that DCs displayed higher IL-6 staining than trophoblasts in CAMcomplicated specimens (HSCORE mean \pm SEM: $201 \pm$ 20 versus $133 \pm 9$, respectively; $P<0.05$ ). In contrast, IL-6 staining intensity was similar in trophoblasts of CAMcomplicated and control specimens (HSCORE mean \pm SEM: $133 \pm 9$ and $130 \pm 8$, respectively; not significant) and in DCs and trophoblasts of control specimens (HSCORE mean \pm SEM: $152 \pm 23$ and $130 \pm 8$, respectively; not significant).

\section{Regulation of IL-6 Protein Expression in DCs}

Elevated circulating $E_{2}$ and progesterone levels during gestation prompted use of $E_{2}$ as the control during parallel incubations of leukocyte-depleted term DCs with $E_{2}$ plus MPA. Figure 2, A and B, displays the results of 12 separate experiments. It indicates that IL-6 levels were similar in conditioned DM of DCs incubated in parallel with $E_{2}\left(0.34 \pm 0.15 \mathrm{pg} / \mathrm{ml} / \mu \mathrm{g}\right.$ of protein) or with $\mathrm{E}_{2}+$ MPA $(0.24 \pm 0.15 \mathrm{pg} / \mathrm{ml} / \mu \mathrm{g}$ of protein); (mean \pm SEM, $n=12$ ). Incubation of $E_{2}$-treated and $E_{2}+$ MPA-treated DCs with $1.0 \mathrm{ng} / \mathrm{ml}$ of IL-1 $\beta$ markedly enhanced IL-6 output to respective $577 \pm 218 \mathrm{pg} / \mathrm{ml} / \mu \mathrm{g}$ of protein $(P<$ $0.05)$ and $157 \pm 35 \mathrm{pg} / \mathrm{ml} / \mu \mathrm{g}$ of protein $(P<0.05)$. The IL-1 $\beta$-enhanced response in incubations with $E_{2}$ of $2474 \pm 586$-fold was reduced to $792 \pm 146$-fold in incubations with $E_{2}+$ MPA. This MPA-mediated blunting of IL-1 $\beta$-augmented IL-6 output proved to be statistically significant $(P<0.05)$.

The Western blot depicted in Figure 3 indicates that the conditioned DM from term DCs incubated with 1 $\mathrm{ng} / \mathrm{ml}$ of IL- $1 \beta$ contains a doublet that corresponds to a previously described major band at 21 to $24 \mathrm{kDa}$ and a minor band at 25 to $29 \mathrm{kDa}$ that arises from differences in O-glycosylation of IL-6. ${ }^{22}$ Inspection of Figure 3 confirms the ELISA results of Figure 2, ie, when compared with $E_{2}$ alone, coincubation with $E_{2}$ and MPA reduced the magnitude of the marked IL-1 $\beta$-mediated increase of the doublet representing IL-6.

Figure 4 displays the effects of increasing concentrations of IL-1 $\beta$ on secreted levels of IL-6 as determined by 
A

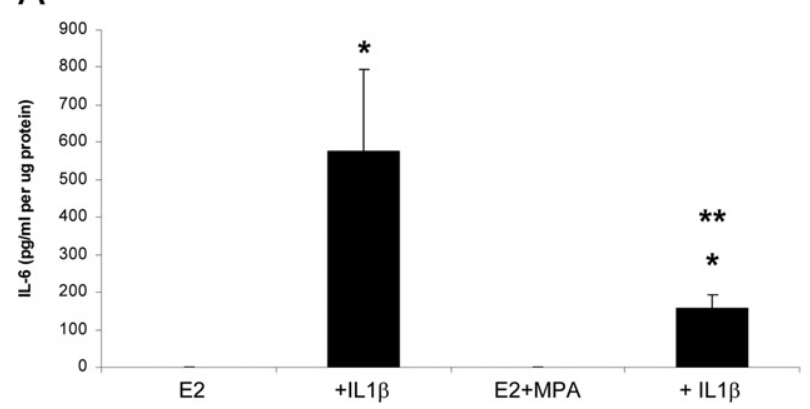

B

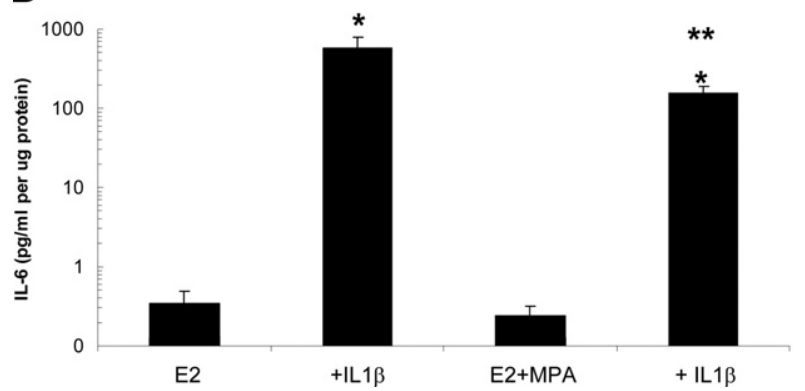

Figure 2. Effects of MPA and IL- $1 \beta$ on IL- 6 output by DC monolayers Confluent, leukocyte-free term DCs were incubated for 7 days in $10^{-8} \mathrm{~mol} / \mathrm{L}$ $\mathrm{E}_{2}$ or $\mathrm{E}_{2}+10^{-7} \mathrm{~mol} / \mathrm{L}$ MPA then switched to DM with corresponding steroid(s) $\pm 1 \mathrm{ng} / \mathrm{ml} \mathrm{IL}-1 \beta$ for 24 hours. IL- 6 levels were measured by ELISA in conditioned DM and normalized to cell protein amount. Decidual specimens were obtained from separate patients $(n=12$; mean \pm SEM). The ordinate represents IL-6 (pg/ml/ $\mu$ g of cell protein) as linear plot (A) and log scale $(\mathbf{B})$. "Versus $\mathrm{E}_{2}$ or $\mathrm{E}_{2}+$ MPA; ${ }^{* * *}$ versus $\mathrm{E}_{2}+\mathrm{IL}-1 \beta(P<0.05)$.

ELISA in leukocyte-free term DCs incubated with $\mathrm{E}_{2}+$ MPA. Exogenous IL-1 $\beta$ elicited a statistically significant concentration-dependent increase in IL-6 output between 0.01 and $10 \mathrm{ng} / \mathrm{ml}$ of exogenous $\mathrm{IL}-1 \beta$.

Figure 5, A and B, indicates that changes in steadystate IL-6 mRNA levels as determined by quantitative real time RT-PCR in term DC monolayers correspond to those of IL-6 protein. Specifically, IL-1 $\beta$ added at $1.0 \mathrm{ng} / \mathrm{ml}$ enhanced IL-6 mRNA levels by $1883 \pm 749$-fold when incubated with $\mathrm{E}_{2}$ alone and by $577 \pm 122$-fold in parallel incubations with $\mathrm{E}_{2}+\operatorname{MPA}(n=8$; mean \pm SEM; $P<$ $0.05)$. As with the effects of MPA on secreted IL-6 protein levels displayed in Figure 2, the blunting exerted by MPA on IL-1 $\beta$-enhanced IL-6 mRNA levels proved to be statistically significant $(P<0.05)$.

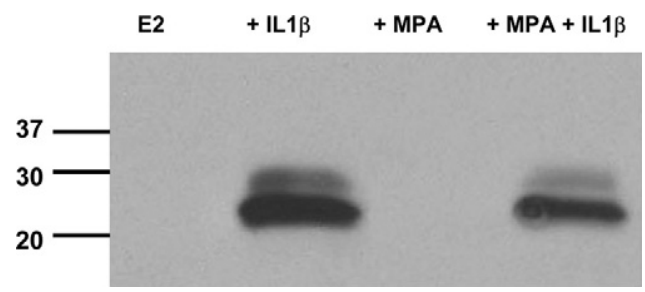

Figure 3. Western blot of MPA and IL-1 $\beta$ effects on IL-6 output by DC monolayers. Confluent, leukocyte-free term DCs were incubated for 7 days in $10^{-8} \mathrm{~mol} / \mathrm{L} \mathrm{E}_{2}$ or $\mathrm{E}_{2}+10^{-7} \mathrm{~mol} / \mathrm{L} \mathrm{MPA}$, then switched to a DM with corresponding steroid(s) $\pm 1 \mathrm{ng} / \mathrm{ml} \mathrm{IL}-1 \beta$ for 24 hours. Conditioned DM was subjected to 10 to $20 \%$ SDS-polyacrylamide gel electrophoresis and Western blotting (see Materials and Methods). A representative blot at a 10-second exposure time is shown. Only the lanes relevant to this study are shown; the others have been omitted from the image.

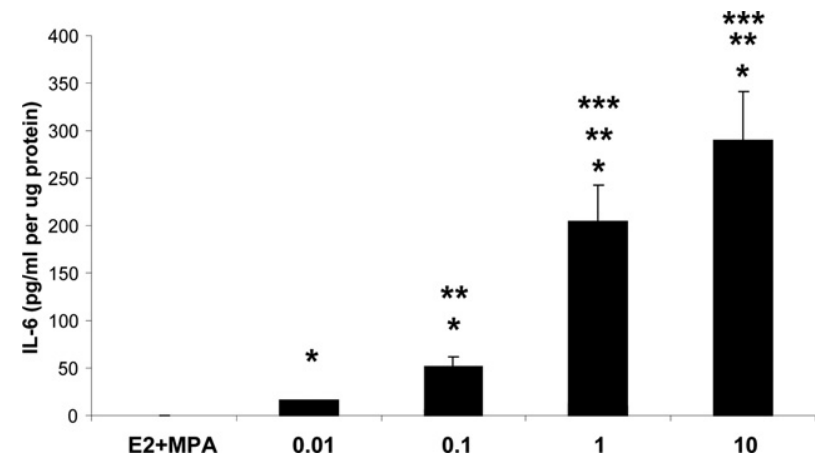

Figure 4. Concentration-dependent effects of IL- $1 \beta$ on IL- 6 output by DC monolayers maintained in $\mathrm{E}_{2}+\mathrm{MPA}$. Confluent, leukocyte-free term trimester DCs were incubated for 7 days in $10^{-8} \mathrm{~mol} / \mathrm{L} \mathrm{E}_{2}+10^{-7} \mathrm{~mol} / \mathrm{L} \mathrm{MPA}$ and then were switched to a DM with steroids \pm the indicated amount of IL- $1 \beta$ $(0.01$ to $10.0 \mathrm{ng} / \mathrm{ml})$. IL-6 levels were measured by ELISA in conditioned DM and normalized to cell protein amount. Decidual specimens were obtained from separate patients $(n=5$, mean \pm SEM $)$. "Versus $\mathrm{E}_{2}+$ MPA; **versus $0.01 \mathrm{ng} / \mathrm{ml} \mathrm{IL}-1 \beta{ }^{* * * * *}$ versus $0.1 \mathrm{ng} / \mathrm{ml} \mathrm{IL}-1 \beta(P<0.05)$.

Figure $6 \mathrm{~A}$ indicates that the specific inhibitors $\mathrm{NF}-\kappa \mathrm{B}$ activation inhibitor III and the p38 MAPK inhibitor SB203580 each blunted IL-1 $\beta$-enhanced secreted IL-6 levels in term DC monolayers incubated with $E_{2}+M P A$ by at least half during incubation with $E_{2}+$ MPA. In contrast, the specific protein kinase $\mathrm{C}$ inhibitor calphostin C did not affect IL-1 $\beta$-enhanced IL-6 output nor did the negative control for the p38 MAPK inhibitor. In addition, Figure $6 \mathrm{~B}$ indicates that none of the inhibitors significantly affected basal IL-6 output. Western blotting confirmed these ELISA results (Figure 7).

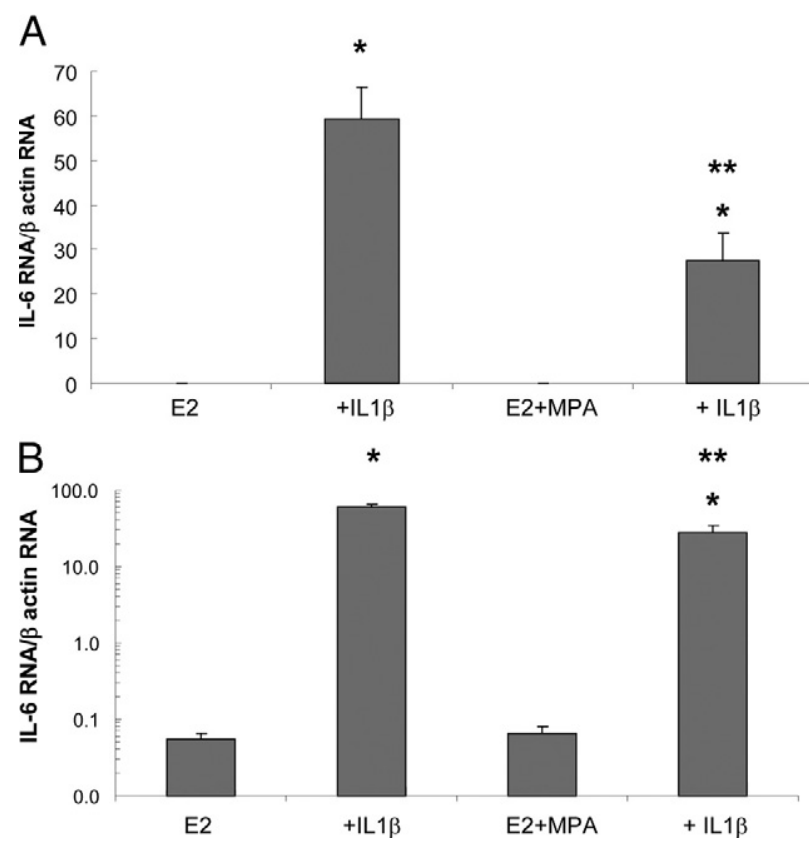

Figure 5. Effects of MPA and IL- $1 \beta$ on IL- 6 mRNA levels in DC monolayers. Confluent leukocyte-free term DCs were incubated for seven days in $10^{-8}$ $\mathrm{mol} / \mathrm{L} \mathrm{E}_{2}$ or $10^{-8} \mathrm{~mol} / \mathrm{L} \mathrm{E}_{2}+10^{-7} \mathrm{~mol} / \mathrm{L} \mathrm{MPA}$ and then were switched to a DM with corresponding steroid(s) $\pm 1 \mathrm{ng} / \mathrm{ml} \mathrm{IL}-1 \beta$ for six hours. Aliquots of extracted total RNA were used to measure IL- 6 mRNA levels by quantitative real-time RT-PCR. Decidual specimens were from separate patients $(n=8$; mean \pm SEM). The ordinate represents IL- $6 \mathrm{mRNA} / \beta$-actin as a linear plot (A) and $\log$ scale $(\mathbf{B})$. *Versus $\mathrm{E}_{2}$ or $\mathrm{E}_{2}+\mathrm{MPA}$; ${ }^{* *}$ versus $\mathrm{E}_{2}+\mathrm{IL}-1 \beta(P<0.05)$. 
A

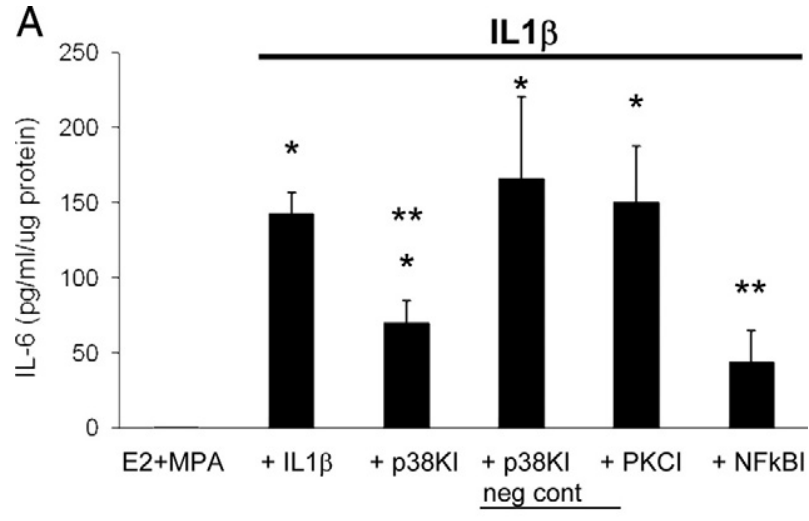

B

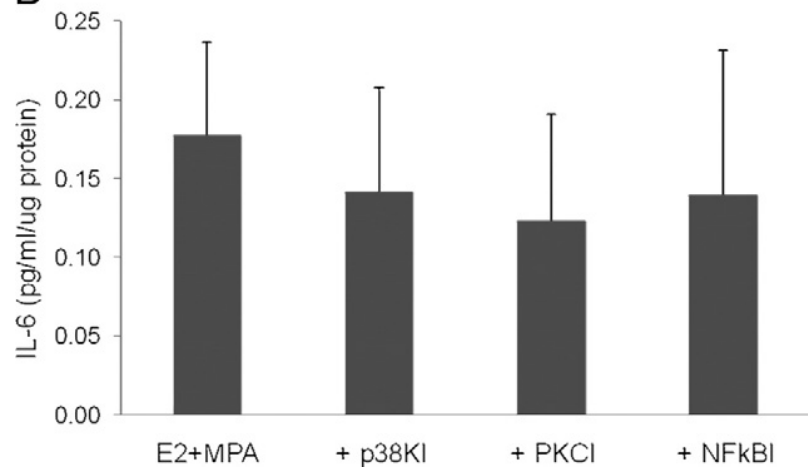

Figure 6. Effects of signaling pathway inhibitors on IL-6 secretion by term DC monolayers. Confluent, leukocyte-free term DCs were incubated for seven days in $10^{-8} \mathrm{~mol} / \mathrm{L} \mathrm{E}_{2}+10^{-7} \mathrm{~mol} / \mathrm{L} \mathrm{MPA}$. Cultures were then switched for 24 hours to a DM with $\mathrm{E}_{2}+\mathrm{MPA} \pm$ signaling pathway inhibitors $\pm 1 \mathrm{ng} / \mathrm{ml} \mathrm{IL}-1 \beta$. The following specific inhibitors were used: $\mathrm{p} 38$ MAPK inhibitor (P38KI; SB203580), protein kinase C inhibitor (PKCI; calphostin $\mathrm{C}$ ), and NF- $\kappa \mathrm{B}$ activation inhibitor (NFkBI). All of the inhibitors were added as pretreatments for 30 to 60 minutes before the addition of IL- $1 \beta$. Levels of IL- 6 were measured by ELISA in conditioned DM and normalized to cell protein amount. Decidual specimens were obtained from separate patients ( $n=6$ each for $\mathrm{E}_{2}+$ MPA and $\mathrm{p} 38 \mathrm{KI}$ groups; $n=3$ each for PCKI and NFkBI groups; mean \pm SEM). The ordinate represents IL- $6(\mathrm{pg} / \mathrm{ml} / \mu \mathrm{g}$ of cell protein). A: Effect of inhibitors on IL- $1 \beta$-induced IL-6. B: Effect of inhibitors on IL-6 under basal conditions $\left(\mathrm{E}_{2}+\mathrm{MPA}\right)$. ${ }^{*}$ Versus $\mathrm{E}_{2}+\mathrm{MPA} ;{ }^{* *}$ versus $\mathrm{E}_{2}+$ MPA + IL-1 $\beta(P<0.05)$. neg cont, negative control.

Figure 8 indicates that in monocyte incubations with conditioned media from term DCs with $\mathrm{E}_{2}$, treatment with an IL-6-neutralizing antibody did not alter the percentage of either CD14-positive macrophages (left panel) or

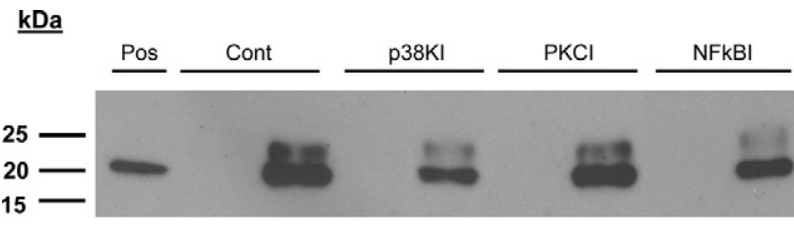

IL1 $\beta$ : +

Figure 7. Western blot of effects of signaling pathway inhibitors on IL-6 secretion by term DC monolayers. Confluent, leukocyte-free term DCs were incubated for seven days in $10^{-8} \mathrm{~mol} / \mathrm{L} \mathrm{E}_{2}+10^{-7} \mathrm{~mol} / \mathrm{L} \mathrm{MPA}$. Cultures were then switched for 24 hours to a DM with $\mathrm{E}_{2}+\mathrm{MPA} \pm$ signaling pathway inhibitors $\pm 1 \mathrm{ng} / \mathrm{ml} \mathrm{IL}-1 \beta$. The following specific inhibitors were used: p38 MAPK inhibitor (P38KI), protein kinase C inhibitor (PKCI), and NF- $\kappa \mathrm{B}$ activation inhibitor (NFkBI). All of the inhibitors were added as pretreatments for 30 to 60 minutes before the addition of IL- $1 \beta$. Conditioned DM was subjected to $12 \%$ SDS-polyacrylamide gel electrophoresis and Western blotting (see Materials and Methods). A representative blot at a 2-minute exposure time is shown. Positive control (Pos Cont): 10 ng of recombinant human IL-6.
CD11c-positive dendritic cells (right panel). However, in parallel monocyte incubations with conditioned media from term DCs with $\mathrm{E}_{2}$ plus IL-1 $\beta$, which elevated secreted levels of IL-6 greater than 2000 -fold in the term DCs (seen in Figure 2), a statistically significant increase in CD14-positive cells was observed (left panel). Furthermore, this increase was blocked by coincubation with an IL-6-neutralizing antibody (left panel). In comparison, the right panel indicates that these monocyte incubations with conditioned media from term DCs with $\mathrm{E}_{2}+\mathrm{IL}-1 \beta$ led to a small nonsignificant increase in numbers of CD11c-bearing cells. Paradoxically, coincubation with the antibody against IL-6 resulted in a statistically significant increase in CD11c-bearing cells.

\section{Discussion}

Elevated IL-6 levels in amniotic fluid, maternal serum, and cervicovaginal secretions each reliably predict preterm birth. ${ }^{12-14,23}$ Augmented IL-6 levels in amniotic fluid in combination with evaluation of cervical characteristics by vaginal sonography and elevated levels of fetal fibronectin in cervicovaginal secretions have proven to be the best method of predicting PTD. ${ }^{24}$ Previous studies suggested that IL-6 derived from human decidual and chorion laeve cells ${ }^{25,26}$ contribute to elevated amniotic fluid IL-6 levels involved in the pathophysiology of infectionrelated PTD. Levels of IL- 6 in the amniotic fluid of women with infection were found to enhance the production of uterine contraction-mediating prostaglandin $E_{2}$ when incubated with amnion or DCs, thereby suggesting a mechanism to account for CAM-associated PTD. ${ }^{27}$

As in our evaluation of preeclamptic versus control decidual specimens, ${ }^{10}$ the current study observed IL-6 immunostaining localized primarily in the cytoplasm of DCs that increased significantly in CAM versus control placental sections (HSCOREs, $P<0.05$ ). In contrast, IL-6 HSCOREs were significantly lower in adjacent interstitial trophoblasts where the staining is primarily perimembranous and similar between patients and control subjects. Consistent with DCs as a source of CAM-related new IL-6 protein synthesis, the current study found that $\mathrm{IL}-1 \beta$ markedly up-regulated IL-6 mRNA and protein expression in leukocyte-free term DC monolayers. These in vivo and in vitro results suggest that DCs, the predominant cell-type in human decidua, contribute to elevated IL-6 levels in maternal serum as well as amniotic fluid during CAM. ${ }^{12,23}$ Incubation with a specific p38 MAPK inhibitor and a specific NF- $\kappa$ B activation inhibitor significantly blunted IL-1 $\beta$-enhanced IL-6 output by term DCs. As for other inflammatory conditions, these results suggest that CAM-associated augmented IL-6 expression in DCs is probably mediated at least in part by both the p38 MAPK and the NF- $\kappa \mathrm{B}$ activation signaling pathways.

As is typical of an initial host-mediated protective response against microbial invasion, during CAM neutrophil trafficking into the decidua promotes acute inflammation. ${ }^{28}$ The previously cited Alabama Preterm Birth Study noted a strong association between positive intrauterine microbial cultures and neutrophil infiltration of the 

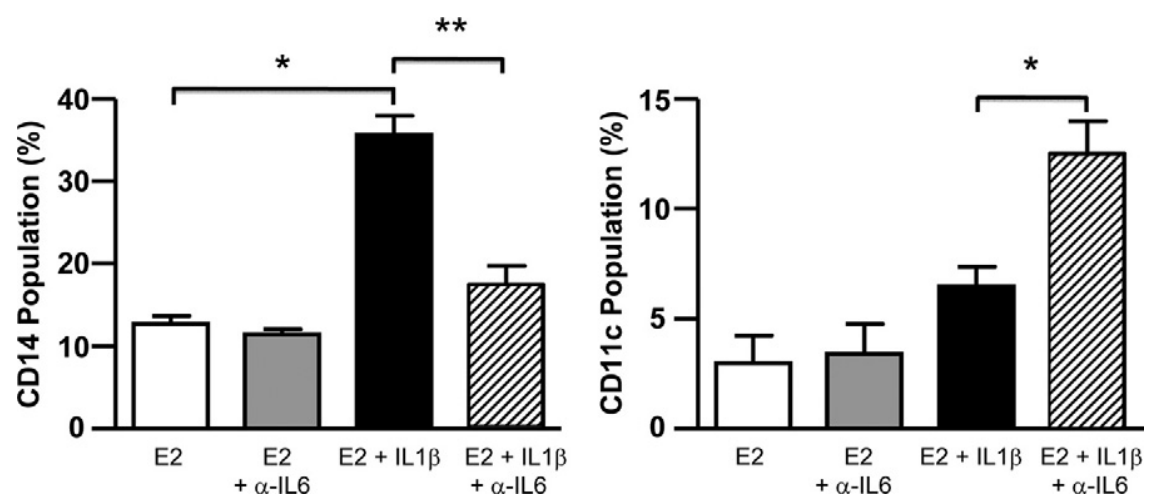

Figure 8. Functional in vitro assay. IL-6 skews monocyte differentiation to macrophages. Monocytes from human peripheral blood were cultured for five days in a combination of conditioned medium obtained from term decidual cells that had been treated for 24 hours with $\mathrm{E}_{2}$ or $\mathrm{E}_{2}+\mathrm{IL}-1 \beta$ in the presence or absence of anti-IL- 6 antibody $(\alpha-$ IL6) and $20 \mathrm{ng} / \mathrm{ml} \mathrm{M-CSF}, 30 \mathrm{ng} / \mathrm{ml} \mathrm{GM-CSF}$, and $10 \mathrm{ng} / \mathrm{ml} \mathrm{IL}-4$. Differentiation was determined at day 5 by the expression of the macrophage markers CD14 (left) and CD68 (data not shown for CD68) and the dendritic cell marker CD11c (right). Data are shown as the mean $\pm \operatorname{SEM}(n=$ 4). ${ }^{*} P<0.05 ;{ }^{* *} P<0.005$.

free membranes, chorionic plate, and umbilical cord. ${ }^{7}$ Consistent with this acute inflammatory response, our laboratory ${ }^{29}$ and that of Dudley ${ }^{30}$ found that in cultured term DCs IL- $1 \beta$ enhances expression of well established neutrophil chemoattractants and activators such as IL-8, epithelial neutrophil-activating peptide (ENA-78), growthrelated oncogene- $\alpha$ (Gro- $\alpha$ ), and granulocyte-chemotactic protein-2 (MCP-2).

As the first immune cells to arrive at inflammatory sites, neutrophils phagocytose and kill invading microorganisms and provide further protection by initiating the acute inflammatory host response via release of reactive oxygen species. ${ }^{31}$ Neutrophils are also a rich source of extracellular matrix (ECM)-degrading proteases such as neutrophil elastase and the matrix metalloproteinases (MMPs) including MMP-8, which preferentially degrades fibrillar collagens, and MMP-9, which degrades basement membrane-associated collagens IV and V. ${ }^{32,33}$ Our previous study ${ }^{34}$ showed that incubation of leukocyte-free term DCs with IL-1 $\beta$ markedly enhanced the expression of MMP-1, which preferentially degrades fibrillar collagens, and MMP-3, which degrades several ECM substrates and can mediate an ECM-degrading cascade by activating secreted pro-MMP-1 and MMP$9^{35,36}$ The interactive effects of a fibrillar collagen-rich ECM scaffolding in the amnion and choriodecidua normally withstands disruptive physical forces stemming from the fetus, amniotic fluid, and myometrial contractions by providing greater than additive tensile strength. ${ }^{37}$ Degradation of these ECMs by proteases derived from neutrophils or DCs impairs this structural integrity to promote PPROM. ${ }^{38}$

Chronic deciduitis in the absence of vilitis as defined by mononuclear cell infiltration of the decidua basalis occurs in 5 to $10 \%$ of placentas and leads to PTD. ${ }^{28}$ In a significant subset of patients, the decidua basalis contains a mononuclear infiltrate composed primarily of plasmocytes (B-lymphocytes) and secondarily of histiocytes (macrophages) that is uniquely associated with severe pathological changes, ie, neonatal intraventricular hemorrhage and death. ${ }^{7}$ Decidual cell-derived IL-6 is likely to play an integral role in promoting this increase in the local monocyte population. Specifically, in several pathological conditions, IL-6 mediates the transition from acute to chronic inflammation by inhibiting neutrophil infiltration. 21,39

During inflammation IL-6 also is involved in promoting monocyte differentiation away from dendritic cells toward macrophages. ${ }^{21,39}$ The existence of this mechanism in human DCs near or at term is indicated by the results of a functional assay presented in Figure 8. Specifically, incubation of monocytes isolated from the circulation with conditioned medium (DM) from IL-1 $\beta$-treated leukocytefree term DC monolayers induced the differentiation of monocytes to macrophages and had a slight but not significant increase on the dendritic cell population. However, preincubation of this same conditioned medium with a specific IL-6-neutralizing antibody blocked this differentiation to macrophages while inducing a reciprocal increase in dendritic cells. This finding suggests that among several agents present in IL- $1 \beta$-treated DC-conditioned medium, IL-6 plays a decisive role in promoting differentiation to macrophages and this conversion is normally kept in check by the presence of excess IL-6.

In addition to neutrophil chemoattractants, human DCs at term express a complex array of other immune cell modulators. These include GM-CSF, which is both a potent neutrophil and macrophage chemoattractant and activator, ${ }^{40}$ as well as the monocyte/macrophage chemoattractant and activators, M-CSF ${ }^{41}$ and monocyte chemoattractant protein-1 (MCP-1). ${ }^{42}$ The decidua of patients with CAM-complicated pregnancies also contains several factors that can alter the immune response. These include i) the initial decidual influx of neutrophils, which can protect against the transition to chronic inflammation and its potential pathological consequences ${ }^{43}$ by expressing Th2 mediators, such as the cytokine inhibitors tumor necrosis factor soluble receptor type 2 and the IL-1 receptor antagonist ${ }^{44}$ and ii) a constitutively expressed excess of macrophage migration inhibitory factor, a 12.5$\mathrm{kDa}$ cytokine that in some contexts inhibits migration and chemotaxis of macrophages. ${ }^{41}$ Moreover, inhibition of IL-6 expression by MPA in cultured term DCs described in the current study suggests a mechanism by which maintenance of high circulating progesterone levels blocks conversion of acute to chronic inflammation in the decidua. The specificity of this progestin-mediated inhibition of IL-6 expression is indicated by our observation that MPA did not affect expression of either GM-CSF, ${ }^{40}$ M-CSF, ${ }^{41} \mathrm{MCP}-1,{ }^{42}$ or IL- ${ }^{29}$ by the DCs.

The severe pathological complications associated with monocyte-associated chronic inflammation in the decidua described in the Alabama Preterm Birth Study were not experienced by the majority of patients with CAM in 
whom infiltration of neutrophils remained dominant. This suggests that persistence of acute local inflammation leading to PTD in most women with CAM may have developed as an evolutionary protective alternative. Uncovering the mechanisms that normally prevent DC-derived IL-6 from promoting a local chronic inflammatory response presents an important challenge. In this regard, human term DCs also express IL-11, ${ }^{45}$ another member of the IL-6 cytokine family, that generally differs from IL-6 in exerting anti-inflammatory actions. ${ }^{46,47}$ The possibility that progestin-induced prolactin expression in DCs protects against IL-6-mediated chronic inflammation deserves investigation. Both rodent and human DCs continue to express prolactin throughout term. ${ }^{48-50}$ The rodent decidua does not normally express IL-6, whereas active IL-6 expression by the decidua of transgenic prolactin or prolactin receptor knockout mice ${ }^{51}$ promotes aberrant local inflammation associated with premature abortion and fetal death ${ }^{51}$ reminiscent of the fetal inflammatory response syndrome in humans, which is characterized by systemic inflammation and elevated fetal plasma IL-6 levels. ${ }^{52}$ Further studies are needed to elucidate the mechanisms underlying the overexpression of decidual cell IL-6 in chorioamnionitis.

\section{Acknowledgments}

We thank Dr. Mizanur Rahman for his expert cell culture work and Ms. Rebeca Caze for her expert immunohistochemical work in this study.

\section{References}

1. Mueller-Heubach E, Rubinstein DN, Schwarz SS: Histologic chorioamnionitis and preterm delivery in different patient populations. Obstet Gynecol 1990, 75:622-626

2. Hamilton BE, Martin JA, Sutton PD: Births: preliminary data for 2003. Natl Vital Stat Rep 2004, 53:1-17

3. Newton ER: Preterm labor, preterm premature rupture of membranes, and chorioamnionitis. Clin Perinatol 2005, 32:571-600

4. Romero R, Mazor M, Wu YK, Sirtori M, Oyarzun E, Mitchell MD, Hobbins JC: Infection in the pathogenesis of preterm labor. Semin Perinatol 1988, 12:262-279

5. Shim SS, Romero R, Hong JS, Park CW, Jun JK, Kim BI, Yoon BH: Clinical significance of intra-amniotic inflammation in patients with preterm premature rupture of membranes. Am J Obstet Gynecol 2004, 191:1339-1345

6. Helmig BR, Romero R, Espinoza J, Chaiworapongsa T, Bujold E, Gomez R, Ohlsson K, Uldbjerg N: Neutrophil elastase and secretory leukocyte protease inhibitor in prelabor rupture of membranes, parturition and intra-amniotic infection. J Matern Fetal Neonatal Med 2002, 12:237-246

7. Andrews WW, Goldenberg RL, Faye-Petersen O, Cliver S, Goepfert AR, Hauth JC: The Alabama Preterm Birth study: polymorphonuclear and mononuclear cell placental infiltrations, other markers of inflammation, and outcomes in 23- to 32-week preterm newborn infants. Am J Obstet Gynecol 2006, 195:803-808

8. Scheller J, Ohnesorge N, Rose-John S: Interleukin-6 trans-signalling in chronic inflammation and cancer. Scand J Immunol 2006, 63:321-329

9. Dunn CL, Kelly RW, Critchley HO: Decidualization of the human endometrial stromal cell: an enigmatic transformation. Reprod Biomed Online 2003, 7:151-161

10. Lockwood CJ, Yen CF, Basar M, Kayisli UA, Martel M, Buhimschi I, Buhimschi C, Huang SJ, Krikun G, Schatz F: Preeclampsia-related inflammatory cytokines regulate interleukin-6 expression in human decidual cells. Am J Pathol 2008, 172:1571-1579

11. Sibai B, Dekker G, Kupferminc M: Pre-eclampsia. Lancet 2005, 365:785-799

12. Maeda K, Matsuzaki N, Fuke S, Mitsuda N, Shimoya K, Nakayama M, Suehara N, Aono T: Value of the maternal interleukin 6 level for determination of histologic chorioamnionitis in preterm delivery. Gynecol Obstet Invest 1997, 43:225-231

13. Jun JK, Yoon BH, Romero R, Kim M, Moon JB, Ki SH, Park JS: Interleukin 6 determinations in cervical fluid have diagnostic and prognostic value in preterm premature rupture of membranes. Am J Obstet Gynecol 2000, 183:868-873

14. Lockwood CJ, Ghidini A, Wein R, Lapinski R, Casal D, Berkowitz RL: Increased interleukin-6 concentrations in cervical secretions are associated with preterm delivery. Am J Obstet Gynecol 1994, 171:1097-1102

15. Saji F, Samejima Y, Kamiura S, Sawai K, Shimoya K, Kimura T: Cytokine production in chorioamnionitis. J Reprod Immunol 2000 47:185-196

16. Kandere-Grzybowska K, Kempuraj D, Cao J, Cetrulo CL, Theoharides TC: Regulation of IL-1-induced selective IL-6 release from human mast cells and inhibition by quercetin. Br J Pharmacol 2006, 148:208-215

17. Walsh MC, Kim GK, Maurizio PL, Molnar EE, Choi Y: TRAF6 autoubiquitination-independent activation of the NF $\kappa$ B and MAPK pathways in response to IL-1 and RANKL. PLoS One 2008, 3:e4064

18. Naeye RL: Maternal age, obstetric complications, and the outcome of pregnancy. Obstet Gynecol 1983, 61:210-216

19. Romero R, Yoon BH, Mazor M, Gomez R, Diamond MP, Kenney JS, Ramirez M, Fidel PL, Sorokin Y, Cotton D, et al: The diagnostic and prognostic value of amniotic fluid white blood cell count, glucose, interleukin-6, and gram stain in patients with preterm labor and intact membranes. Am J Obstet Gynecol 1993, 169:805-816

20. Arici A, Marshburn PB, MacDonald PC, Dombrowski RA: Progesterone metabolism in human endometrial stromal and gland cells in culture. Steroids 1999, 64:530-534

21. Chomarat P, Banchereau J, Davoust J, Palucka AK: IL-6 switches the differentiation of monocytes from dendritic cells to macrophages. Nat Immunol 2000, 1:510-514

22. Gross V, Andus T, Castell J, Vom Berg D, Heinrich PC, Gerok W: Oand $\mathrm{N}$-glycosylation lead to different molecular mass forms of human monocyte interleukin-6. FEBS Lett 1989, 247:323-326

23. Dudley DJ, Hunter C, Mitchell MD, Varner MW: Clinical value of amniotic fluid interleukin-6 determinations in the management of preterm labour. Br J Obstet Gynaecol 1994, 101:592-597

24. Krupa FG, Faltin D, Cecatti JG, Surita FG, Souza JP: Predictors of preterm birth. Int J Gynaecol Obstet 2006, 94:5-11

25. Dudley DJ, Trautman MS, Araneo BA, Edwin SS, Mitchell MD: Decidual cell biosynthesis of interleukin-6: regulation by inflammatory cytokines. J Clin Endocrinol Metab 1992, 74:884-889

26. Dudley DJ, Trautman MS, Edwin SS, Lundin-Schiller S, Mitchell MD: Biosynthesis of interleukin- 6 by cultured human chorion laeve cells: regulation by cytokines. J Clin Endocrinol Metab 1992, 75:1081-1086

27. Mitchell MD, Dudley DJ, Edwin SS, Schiller SL: Interleukin-6 stimulates prostaglandin production by human amnion and decidual cells. Eur J Pharmacol 1991, 192:189-191

28. Redline RW: Placental inflammation. Semin Neonatol 2004, 9:265-274

29. Lockwood CJ, Arcuri F, Toti P, Felice CD, Krikun G, Guller S, Buchwalder LF, Schatz F: Tumor necrosis factor- $\alpha$ and interleukin- $1 \beta$ regulate interleukin-8 expression in third trimester decidual cells: implications for the genesis of chorioamnionitis. Am J Pathol 2006, 169:1294-1302

30. Dudley DJ, Trautman MS, Mitchell MD: Inflammatory mediators regulate interleukin-8 production by cultured gestational tissues: evidence for a cytokine network at the chorio-decidual interface. J Clin Endocrinol Metab 1993, 76:404-410

31. Weiss SJ: Tissue destruction by neutrophils. N Engl J Med 1989, 320:365-376

32. Maymon E, Romero R, Pacora P, Gomez R, Athayde N, Edwin S, Yoon $\mathrm{BH}$ : Human neutrophil collagenase (matrix metalloproteinase 8) in parturition, premature rupture of the membranes, and intrauterine infection. Am J Obstet Gynecol 2000, 183:94-99

33. Van den Steen PE, Proost P, Wuyts A, Van Damme J, Opdenakker G: Neutrophil gelatinase B potentiates interleukin-8 tenfold by aminoterminal processing, whereas it degrades CTAP-III, PF-4, and GRO- $\alpha$ and leaves RANTES and MCP-2 intact. Blood 2000, 96:2673-2681

34. Oner C, Schatz F, Kizilay G, Murk W, Buchwalder LF, Kayisli UA, Arici 
A, Lockwood CJ: Progestin-inflammatory cytokine interactions affect matrix metalloproteinase- 1 and -3 expression in term decidual cells: implications for treatment of chorioamnionitis-induced preterm delivery. J Clin Endocrinol Metab 2008, 93:252-259

35. Westermarck J, Kahari VM: Regulation of matrix metalloproteinase expression in tumor invasion. FASEB J 1999, 13:781-792

36. Nagase H, Visse R, Murphy G: Structure and function of matrix metalloproteinases and TIMPs. Cardiovasc Res 2006, 69:562-573

37. Moore RM, Mansour JM, Redline RW, Mercer BM, Moore JJ: The physiology of fetal membrane rupture: insight gained from the determination of physical properties. Placenta 2006, 27:1037-1051

38. Parry S, Strauss JF 3rd: Premature rupture of the fetal membranes. N Engl J Med 1998, 338:663-670

39. Kaplanski G, Marin V, Montero-Julian F, Mantovani A, Farnarier C: IL-6: a regulator of the transition from neutrophil to monocyte recruitment during inflammation. Trends Immunol 2003, 24:25-29

40. Arcuri F, Toti P, Buchwalder L, Casciaro A, Cintorino M, Schatz F, Rybalov B, Lockwood CJ: Mechanisms of leukocyte accumulation and activation in chorioamnionitis: interleukin $1 \beta$ and tumor necrosis factor $\alpha$ enhance colony stimulating factor 2 in term decidua. Reprod Sci 2009, 16:453-461

41. Arcuri F, Buchwalder L, Toti P, Cintorino M, Tosi P, Lockwood CJ, Rybalov B, Schatz F: Differential regulation of colony stimulating factor 1 and macrophage migration inhibitory factor expression by inflammatory cytokines in term human decidua: implications for macrophage trafficking at the fetal-maternal interface. Biol Reprod 2007, 76:433-439

42. Lockwood CJ, Matta P, Krikun G, Koopman LA, Masch R, Toti P, Arcuri F, Huang ST, Funai EF, Schatz F: Regulation of monocyte chemoattractant protein-1 expression by tumor necrosis factor- $\alpha$ and interleukin- $1 \beta$ in first trimester human decidual cells: implications for preeclampsia. Am J Pathol 2006, 168:445-452

43. Marin V, Montero-Julian FA, Gres S, Boulay V, Bongrand P, Farnarier C,
Kaplanski G: The IL-6-soluble IL-6R $\alpha$ autocrine loop of endothelial activation as an intermediate between acute and chronic inflammation: an experimental model involving thrombin. J Immunol 2001, 167:34353442

44. Xing L, Remick DG: Neutrophils as firemen, production of anti-inflammatory mediators by neutrophils in a mixed cell environment. Cell Immunol 2004, 231:126-132

45. Cakmak H, Schatz F, Huang ST, Buchwalder L, Rahman M, Arici A, Lockwood CJ: Progestin suppresses thrombin- and interleukin- $1 \beta$ induced interleukin-11 production in term decidual cells: implications for preterm delivery. J Clin Endocrinol Metab 2005, 90:5279-5286

46. Cork BA, Tuckerman EM, Li TC, Laird SM: Expression of interleukin (IL)-11 receptor by the human endometrium in vivo and effects of IL-11, IL-6 and LIF on the production of MMP and cytokines by human endometrial cells in vitro. Mol Hum Reprod 2002, 8:841-848

47. Trepicchio WL, Bozza M, Pedneault G, Dorner AJ: Recombinant human IL-11 attenuates the inflammatory response through downregulation of proinflammatory cytokine release and nitric oxide production. J Immunol 1996, 157:3627-3634

48. Gibori G, Rothchild I, Pepe GJ, Morishige WK, Lam P: Luteotrophic action of decidual tissue in the rat. Endocrinology 1974, 95:1113-1118

49. Jabbour HN, Critchley HO: Potential roles of decidual prolactin in early pregnancy. Reproduction 2001, 121:197-205

50. Richards RG, Brar AK, Frank GR, Hartman SM, Jikihara H: Fibroblast cells from term human decidua closely resemble endometrial stromal cells: induction of prolactin and insulin-like growth factor binding protein-1 expression. Biol Reprod 1995, 52:609-615

51. Bao L, Tessier C, Prigent-Tessier A, Li F, Buzzio OL, Callegari EA, Horseman ND, Gibori G: Decidual prolactin silences the expression of genes detrimental to pregnancy. Endocrinology 2007, 148:2326-2334

52. Gotsch F, Romero R, Kusanovic JP, Mazaki-Tovi S, Pineles BL, Erez O, Espinoza J, Hassan SS: The fetal inflammatory response syndrome. Clin Obstet Gynecol 2007, 50:652-683 